\title{
Vegetable and Mineral Used Oils as Cutting Fluids: Effect on Surface Roughness of Aluminum Alloy
}

\author{
Nabeel Gharaibeh \\ Mechanical Engineering Department, Al-Balqa Applied University, Al-Huson University College, Irbid, Jordan \\ Email: nabeelgharaibeh@yahoo.com
}

How to cite this paper: Gharaibeh, N. (2016) Vegetable and Mineral Used Oils as Cutting Fluids: Effect on Surface Roughness of Aluminum Alloy. Journal of Surface Engineered Materials and Advanced Technology, 6, 176-182.

http://dx.doi.org/10.4236/jsemat.2016.64016

Received: August 9, 2016

Accepted: October 9, 2016

Published: October 12, 2016

Copyright (C) 2016 by author and Scientific Research Publishing Inc. This work is licensed under the Creative Commons Attribution International License (CC BY 4.0).

http://creativecommons.org/licenses/by/4.0/

\section{(c) (†) Open Access}

\begin{abstract}
The use of cutting fluids in mechanical machining operation is important to make cutting easy, produce low surface roughness, increase the rate of productivity, and alleviate the negative effect on work environment and operators. In this project the effect of using different cutting fluids on the surface roughness of aluminum alloy (T6-6061) was studied. The experiment involved the use of constant cutting parameters (cutting speed of $860 \mathrm{rpm}$, depth of cut at $1.5 \mathrm{~mm}$, and feed rate of 0.12 $\mathrm{mm} / \mathrm{rev}$ ). Three local cutting fluids: mineral used oil, kerosene, and natural used oil (refined sunflower oil) mixed with water at different ratios $(5 \%, 10 \%, 15 \%, 20 \%$, and $25 \%$ ) were used to study their effect on the surface roughness compared to a common lubricate oil used in the cooling process. Results revealed that mineral used oil gave the lowest (best) roughness coefficient at $5 \%$ water ratio followed by lubricate oil. Kerosene and natural oil had the highest roughness coefficients. Mineral oil could be recommended for use with local cutting machines reducing the huge amounts of waste oil produced in the country.
\end{abstract}

\section{Keywords}

Cutting Fluid, Surface Roughness, Lubrication

\section{Introduction}

Lubricants or cutting fluids are oils and or fluids used to facilitate the motion of cutting machines. The purpose of using lubricating materials is to minimize friction and wear between interacting surfaces and to improve resulting surface finish, and increase tool life. In addition oils are used to decrease heat, prevent corrosion, transfer power, and to remove wear particles. Cutting fluids are of three main types: mineral, semi-synthetic, and synthetic. Generally lubricants are mixed with specific ratio of water to enhance lubricating oil to increase the coverage of surface and to decrease effect of temperature 
(resist thermal breakdown). However, water is a good conductor of heat but its boiling temperature is low and cause rusting of moving parts and therefore it is not a good lubricant [1].

Cutting fluids, if not properly handled, may cause health hazards including skin diseases, exposure to heavy metals, and respiratory problems due to inhalation of toxic materials. When inappropriately discharged, cutting fluids can also cause serious environmental problems such as water resources pollution In addition, cutting fluids cost more than cutting tools [2] [3].

Being biodegradable and non-toxic, the use of vegetable oils as lubricants offers efficient way of minimizing waste and reducing health hazards. Many researchers studied the use of different types of vegetable oils such as rapeseed, canola, and coconut oil as an alternative for mineral oil [4].

Many scientists tested different type of lubricants and their effect on surface roughness of different surfaces. For example different types of sunflower vegetable oils were test compared to two commercial types. The use of such oils was reported to decrease surface roughness value at varying spindle speeds and feed rates during cutting [5]. In another study sunflower oil was compared to standard lubricant on brass alloys. Natural oil (sunflower) results were comparable to that of the standard lubricant with its advantage of having lower cost [6]. The effect of minimum quantity lubrication (MQL) on tool wear and surface roughness used for cutting steel was also investigated. The concept of MQL is important since the use of waste fluids is an important issue in minimization of hazard waste [7].

The objective of this work is to determine the influence of vegetable and mineral used oils as cutting fluids on surface roughness aluminum alloy during the use conventional turning machine.

\section{Materials \& Methods}

\subsection{Aluminum in General}

Aluminum is one the most common metals in Earth's crust, and the second in manufacturer industry. Aluminum alloy T6-6061 is widely used in the industry such as transportation components, machinery equipment, bicycle frames, and fly fishing reels. The mechanical properties of 6061 depend greatly on the temperature, or heat treatment of the material. Young's Modulus is (69 GPa) regardless of temperature. Moreover, T6 temper 6061 has an ultimate tensile strength of at least (300 MPa) and yield strength of at least $(241 \mathrm{MPa})$. More typical values are (310 MPa) and (275 MPa), respectively. In thicknesses $(6.35 \mathrm{~mm})$ or less, it has elongation of $8 \%$ or more; in thicker sections, it has elongation of $10 \%$. T651 temper has similar mechanical properties. The typical value for thermal conductivity for $6061-\mathrm{T} 6$ at $77^{\circ} \mathrm{F}$ is around $152 \mathrm{~W} / \mathrm{m} \mathrm{K}$. A material data sheet defines the fatigue limit under cyclic load as (100 MPa) for $500,000,000$ completely reversed cycles using a standard RR Moore test machine and specimen. Note that aluminum does not exhibit a well-defined "knee" on its S-n graph, so there is some debate as to how many cycles equates to "infinite life". Also note the 
actual value of fatigue limit for an application can be dramatically affected by the conventional de-rating factors of loading, gradient, and surface finish (chemical composition of aluminum alloy is shown in Table 1).

\subsection{Surface Roughness Measurement}

Surface roughness is a component of surface texture. It is calculated by the deviations in the direction of the normal of a real surface from its ideal form. If these deviations are large, the surface is rough; if they are small, the surface is smooth. There are many different roughness parameters in use, but $\mathrm{Ra}$ is by far the most common one. Although a high roughness value is often undesirable, it can be difficult and expensive to control in manufacturing. Decreasing the roughness of a surface will usually increase its manufacturing costs. This often results in a trade-off between the manufacturing cost of a component and its performance in application. Surface roughness $(\mathrm{Ra})$ is the arithmetic average of the roughness profile RT-10 roughness tester (SM Metrology Systems) and cut off number was $0.8 \mathrm{~mm}$ and resolution of $0.001 \mu \mathrm{m}$.

\subsection{Treatments}

Aluminum alloy (T6-6061) was cut into $100 \mathrm{~mm}$ length with a diameter of $20 \mathrm{~mm}$. Lathe machine was used with $860 \mathrm{rpm}$ spindle speed, $0.12 \mathrm{~mm} / \mathrm{rev}$ feed rate, and 1.5 $\mathrm{mm}$ depth of cut. Natural used oil, mineral used oil, kerosene, and lubricate oil were mixed with varying ratios of water $(5 \%, 10 \%, 15 \%, 20 \%$, and $25 \%)$ were used as cutting fluids.

Obtained results showed that mineral used oil had the best surface roughness value (@ 5\% water ratio) therefore this oil was tested at higher spindle speed (1400 rpm) using the same feed rate and depth of cut. Surface roughness at cutting speed $1400 \mathrm{rpm}$ spindle speed, $0.12 \mathrm{~mm} / \mathrm{rev}$ feed rate, and $1.5 \mathrm{~mm}$ depth of cut was then used for mineral used oil and lubricate oil at varying ratios of water (5\%,10\%,15\%,20\%, and 25\%). Values of surface roughness are given in Table 2.

Table 1. Chemical composition of aluminum alloy T6-6061.

\begin{tabular}{ccc}
\hline \multirow{2}{*}{ Elemental content } & Minimum & Maximum \\
\cline { 2 - 3 } & 0.4 & Weight (\%) \\
\hline Silicon & - & 0.8 \\
Iron & 0.15 & 0.7 \\
Copper & - & 0.4 \\
Manganese & 0.8 & 0.15 \\
Magnesium & 0.04 & 1.2 \\
Chromium & - & 0.35 \\
Zinc & - & 0.25 \\
Titanium & no more than $0.05 \%$ each, $0.15 \%$ total \\
Other elements & \multicolumn{2}{c}{0.15} \\
Remainder Aluminum & \multicolumn{2}{c}{. }
\end{tabular}

a. Sample of a Table footnote (Table footnote is dispensable). 
Table 2. Surface roughness at cutting speed $1400 \mathrm{rpm}$.

\begin{tabular}{ccc}
\hline Water:Fluid Ratio & Lubricate Oil & Mineral Used Oil \\
\hline 0 & 1.5 & \\
5 & & 0.98 \\
10 & 1.04 \\
15 & 0.96 \\
20 & 1.15 \\
25 & 1.2 \\
\hline
\end{tabular}

\section{Results \& Discussion}

Surface roughness of the work material fluctuated and increased slightly with water fluid ratio (Figure 1). The graphical relationship shown in Figure 1 was the average value of three measurements taken every time the experiment was stopped. Figure 1 also shows that the range of surface roughness value for each coolant condition varies. For example, the ranges of surface roughness were between $0.845 \mu \mathrm{m}$ to $4.14 \mu \mathrm{m}$. For vegetable (natural) used oil coolant, the ranges of surface roughness were between 3.08 $\mu \mathrm{m}$ to $4.14 \mu \mathrm{m}$. With mineral used oil, the ranges of surface roughness were between $0.845 \mu \mathrm{m}$ to $1.1 \mu \mathrm{m}$, for kerosene, the range values of surface roughness were between $1.88 \mu \mathrm{m}$ to $2.3 \mu \mathrm{m}$ and for new trade mark lubricate oil; the range values of surface roughness were between $1.6 \mu \mathrm{m}$ to $2.02 \mu \mathrm{m}$.

The best (lowest roughness) roughness values were obtained in mineral used oil $(0.845 \mu \mathrm{m})$ at $5 \%$ water: fluid ratio, lubricate oil $(1.6 \mu \mathrm{m})$ at $5 \%$ water: fluid ratio, kerosene $(1.88 \mu \mathrm{m})$ at $25 \%$ water: fluid ratio, and vegetable oil $(3.08 \mu \mathrm{m})$ at $15 \%$ water: fluid ratio. The highest surface roughness in natural used oil was $(4.14 \mu \mathrm{m})$ at $10 \%$ water: fluid ratio, kerosene $(2.3 \mu \mathrm{m})$ at $5 \%$ water: fluid ratio, lubricate oil $(2.02 \mu \mathrm{m})$ at $25 \%$ water: fluid ratio, and Mineral oil $(1.1 \mu \mathrm{m})$ at $25 \%$ water: fluid ratio.

Increasing the (water: fluid ratio) yielded inconsistent results regarding the value of the surface roughness. Chipping was not performed since aluminum has plasticity nature and there was no fragmented chips were observed; only continuous long chips were resulted during cutting process. According the obtained results the best roughness was obtained in mineral used oil at 5\% water: fluid ratio using cutting speed of $860 \mathrm{rpm}$ and depth of cut of $1.5 \mathrm{~mm}$ and feed rate of $0.12 \mathrm{~mm} / \mathrm{rev}$ ). Therefore based on these results; the cutting speed was increased to $1860 \mathrm{rpm}$ using the same depth of cut and feed rate. The observed changes in surface roughness were increased from $0.98 \mu \mathrm{m}$ to about $1.2 \mu \mathrm{m}$ (Table 2).

The temperature could have increased gradually with speed, feed and depth of cut. In an earlier work (Mishra, 1969) it was explained that cutting forces decrease with speed and that since quantity of heat is the product of force and velocity it follows that more heat will be generated with increase in speed. Also at low cutting speeds the principal factor affecting tool-chip interface temperature is the deformation at the shear zone, 

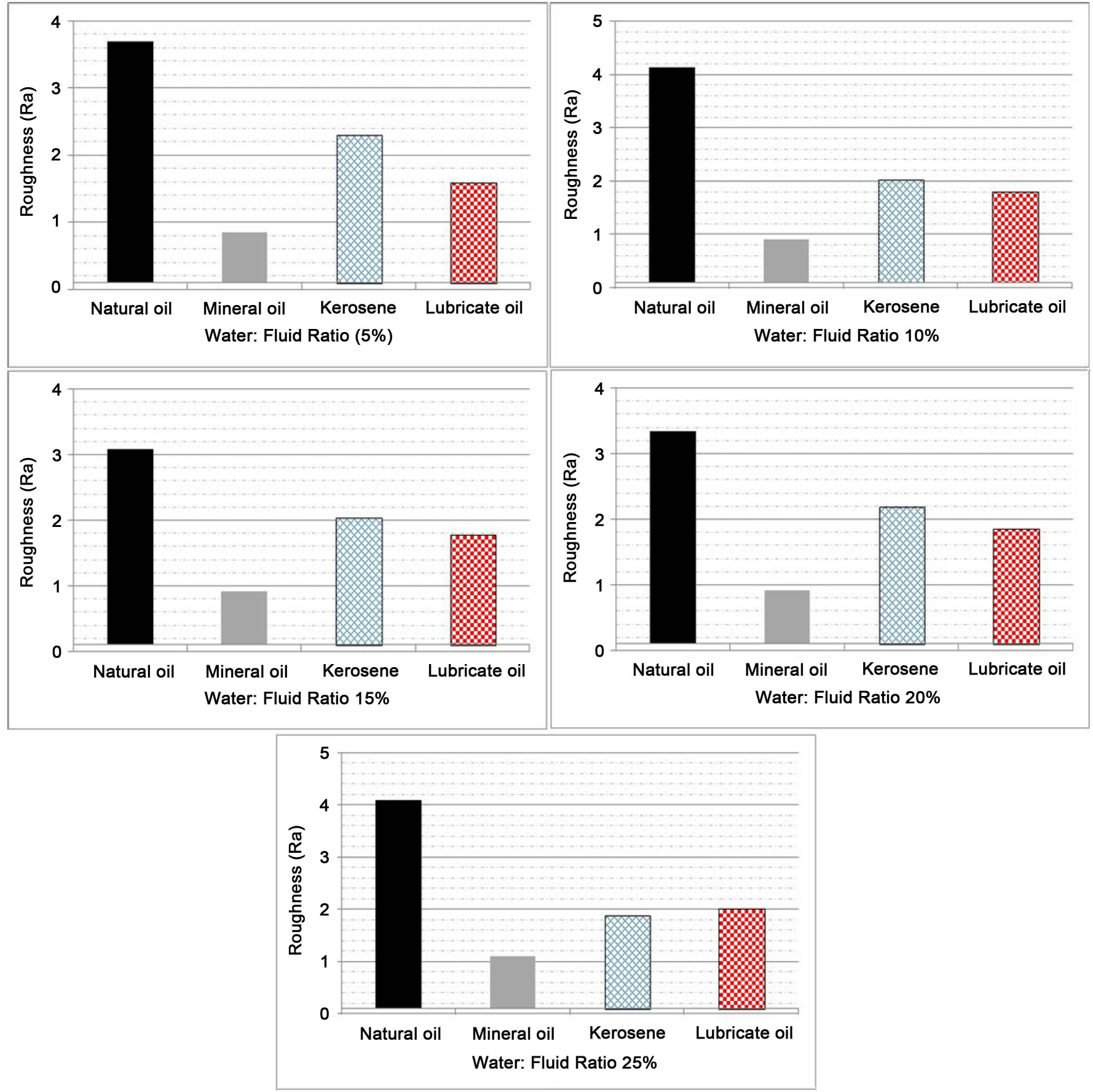

Figure 1. Effect of different types of coolants and water: fluid ratio on surface roughness.

while at high cutting speeds the tool-chip friction is the important factor in the interface temperature. Natural used oil performed the worse than the other used coolants, this is may be due heterogeneous nature of this lubricant, presence of solid particles coming from burned organic materials (food), and presence of fatty acids [8] which could have effective effect as boundary lubricants were also burned. Moreover, there was intermittent flow during pumping, and the oil did not cover fully surface. Kerosene 
on the other hand, performed better than the used natural oil probably due its volatile nature which made penetration to the tool-work piece interface faster and hence better heat reduction. Kerosene is not lubricant and performed the third in terms of surface roughness after lubricate and used mineral oil and this may be due to dryness of the surface after repeated use which in term increased surface roughness compared to mineral and lubricate oil.

When the speed was increased, the rate of heat reduction capability obtained in this work most probably was decreased and therefore the surface roughness increased [9]. Still the obtained results were comparable to lubricate oil. Based on the study, it was conducted that influence of machining conditions on surface roughness concluded that the significant effects for surface roughness was cutting speed. The study showed that coolant concentration does not significantly affect the surface roughness. Machining at lower cutting speed resulted in better surface roughness.

\section{Acknowledgements}

The author would like to thank Eng. Ala'a Elrye'es form faculty of engineering, Balqa University and Eng. Abdullah Shbool from faculty of engineering, Jordan University of Science and Technology for performing lab analysis.

\section{References}

[1] Boyde, S. (2002) Green Lubricants. Environmental Benefits and Impacts of Lubrication, Uniqema Lubricants. Green Chemistry, 4, 293-307. http://dx.doi.org/10.1039/b202272a

[2] Braga, D.U., Diniz, A.E., Miranda, G.W.A. and Coppini, N.L. (2002) Using a Minimum Quantity of Lubricant (MQL) and a Diamond Coated Tool in the Drilling of AluminumSilicon Alloys. Journal of Materials Processing Technology, 122, 127-138. http://dx.doi.org/10.1016/S0924-0136(01)01249-3

[3] Soković, M. and Mijanović, K. (2001) Ecological Aspects of Cutting Fluids and Its Influence on Quantifiable Parameters of the Cutting Processes. Journal of Materials Processing Technology, 109, 181-189. http://dx.doi.org/10.1016/S0924-0136(00)00794-9

[4] Skerlos, S.J., Hayes, K.F., Clarens, A.F. and Zhao, F. (2008) Current Advances in Sustainable Metalworking Fluids Research. International Journal of Sustainable Manufacturing, 1, 180-202. http://dx.doi.org/10.1504/IJSM.2008.019233

[5] Kuram, E., Ozcelik, B., Demirbas, E. and Şık, E. (2010) Effects of the Cutting Fluid Types and Cutting Parameters on Surface Roughness and Thrust Force. Proceedings of the World Congress on Engineering, Vol II, London, 30 June-2 July 2010, 4 p.

[6] Hussein, S.G. (2010) An Experimental Study of the Effects of Coolant Fluid on Surface Roughness in Turning Operation for Brass Alloy. Journal of Engineering, 20, 3.

[7] Dhar, N.R., Kamruzzaman, M. and Ahmed, M. (2006) Effect of Minimum Quantity Lubrication (MQL) on Tool Wear and Surface Roughness in Turning AISI-4340 Steel. Journal of Materials Processing Technology, 172, 299-304. http://dx.doi.org/10.1016/j.jmatprotec.2005.09.022

[8] Kuram, E., Ozcelik, B. and Demirbas, E. (2013) Environmentally Friendly Machining: Vegetable Based Cutting Fluids. In: Davim, J.P., Ed., Green Manufacturing Processes and Systems, Materials Forming, Machining and Tribology, Springer-Verlag Berlin Heidelberg, 2347. http://dx.doi.org/10.1007/978-3-642-33792-5_2 
[9] Gokkaya, H. and Taskesen, A. (2008) The Effects of Cutting Speed and Feed Rate on Bue-Bul Formation, Cutting Forces and Surface Roughness When Machining Aa6351 (T6) Alloy. Journal of Mechanical Engineering, 54, 521-530.

Submit or recommend next manuscript to SCIRP and we will provide best service for you:

Accepting pre-submission inquiries through Email, Facebook, LinkedIn, Twitter, etc. A wide selection of journals (inclusive of 9 subjects, more than 200 journals)

Providing 24-hour high-quality service

User-friendly online submission system

Fair and swift peer-review system

Efficient typesetting and proofreading procedure

Display of the result of downloads and visits, as well as the number of cited articles

Maximum dissemination of your research work

Submit your manuscript at: http://papersubmission.scirp.org/

Or contact jsemat@scirp.org 